Andrews University

Digital Commons @ Andrews University

Faculty Publications

3-1-2005

\title{
Differential Rhizosphere Establishment and Cyanide Production by Alginate-formulated Weed-deleterious Rhizobacteria
}

Horace G. Gurley

Andrews University

Robert E. Zdor

Andrews University, zdor@andrews.edu

Follow this and additional works at: https://digitalcommons.andrews.edu/pubs

Part of the Weed Science Commons

\section{Recommended Citation}

Gurley, Horace G. and Zdor, Robert E., "Differential Rhizosphere Establishment and Cyanide Production by Alginate-formulated Weed-deleterious Rhizobacteria" (2005). Faculty Publications. 2053.

https://digitalcommons.andrews.edu/pubs/2053

This Article is brought to you for free and open access by Digital Commons @ Andrews University. It has been accepted for inclusion in Faculty Publications by an authorized administrator of Digital Commons @ Andrews University. For more information, please contact repository@andrews.edu. 


\title{
Differential Rhizosphere Establishment and Cyanide Production by Alginate-Formulated Weed-Deleterious Rhizobacteria
}

\author{
Horace G. Gurley,* Robert E. Zdor \\ Department of Biology, Andrews University, Berrien Springs, MI 49104, USA
}

Received: 21 July 2004 / Accepted: 18 October 2004

\begin{abstract}
The effects of Pseudomonas putida ATH2-1RI/9 and Acidovorax delafieldii ATH2-2RS/1 on rhizosphere colonization, cyanide production, and growth of velvetleaf and corn was examined. When formulated in alginate beads and inoculated onto velvetleaf and corn plants ( $10^{9} \mathrm{CFU} /$ plant), only $P$. putida ATH2-1RI/9 consistently reduced velvetleaf growth. Neither isolate inhibited corn growth. Interestingly the levels of $P$. putida ATH2-1RI/9 in the velvetleaf rhizosphere were 1000-fold higher (7 $\times 10^{7} \mathrm{CFU} / \mathrm{g}$ root) than the A. delafieldii ATH2-2RS/1 populations. Cyanide (53-68 mM/g root) was recovered from the $P$. putida ATH2-1RI/9-inoculated velvetleaf plants. In contrast both A. delafieldii ATH2-2RS/1 and $P$. putida ATH2-1RI/9 colonized the corn rhizosphere to the same extent $\left(1-5 \times 10^{7}\right.$ $\mathrm{CFU} / \mathrm{g}$ root), producing $1 \mathrm{mM}$ and $14 \mathrm{mM} / \mathrm{g}$ root respectively. These results suggest that bacterial formulation methods can influence the effectiveness of deleterious rhizobacteria in reducing weed growth.
\end{abstract}

The introduction of bacteria into soil for weed control requires that the organisms survive and multiply under field conditions. van Veen et al. [23] noted that for microbes to be successful in the biological control of pest plants, colonization of soil and plant roots needs to be sufficiently high for the intended purpose. Several releases of microorganisms into soils, including microbes for weed control, have been successful [7, 14]. Kennedy et al. [11] found the introduction of weeddeleterious rhizobacteria (WRB) into soil effectively reduced downy brome growth in the field. A variety of liquid and solid formulations have been devised to promote rhizobacterial persistence in inoculated soil [9]. The semolina-flour-based granular formation termed "pesta" has been used successfully in formulating WRB for green foxtail [8]. Cell encapsulation in sodium alginate has been used to protect cells from environmental stresses, promoting bacterial survival and releasing the microbe slowly into the soil during poly-

*Present address: Department of Biology, Western Michigan University, Kalamazoo, MI 49008, USA

Correspondence to: R.E. Zdor; email: zdor@andrews.edu mer degradation $[4,5,20,21,26]$. Relatively few studies describing the formulation of WRB in alginate have been published and none have addressed the success of alginate-formulated WRB in weed suppression [13].

The current study involved the use of alginateencapsulated formulations of two cyanogenic bacterial isolates with biological control potential for the weed velvetleaf (Abutilon theophrasti). Pseudomonas putida ATH2-RI/9 and Acidovorax delafieldii ATH2-2RS/1 were recovered from velvetleaf roots and reduce the growth of liquid-inoculated velvetleaf plants, but not corn plants, grown in autoclaved soil [16]. Cyanogenesis is a phenotype associated with plant suppression and may contribute to the ability of certain WRB to suppress weeds $[1,2,12]$. Due to changes that occur during the growth of bacteria [25], both stationary growth phase (SGP) and logarithmic growth phase (LGP) cells were formulated. The establishment of rhizosphere bacterial populations and cyanide levels and the accompanying effects on plant growth were used as indicators of bacterial compatibility with the alginate formulation. 
Table 1. Velvetleaf and corn rhizosphere colonization of weed deleterious bacteria. Levels of both logarithmic and stationary phase RS (Acidovorax delafieldii ATH2-2RS/1) bacteria were significantly $(p<0.05)$ lower on velvetleaf, but not corn, roots as compared with RI (Pseudomonas putida ATH2-1RI/9) bacteria. $n=10-12$ plants from three independent experiments

\begin{tabular}{|c|c|c|c|c|}
\hline \multirow[b]{3}{*}{ Bacterial growth phase } & \multicolumn{4}{|c|}{ Mean $\pm 1 \mathrm{SE} \mathrm{CFU/g} \mathrm{root}$} \\
\hline & \multicolumn{2}{|c|}{ Velvetleaf roots } & \multicolumn{2}{|c|}{ Corn roots } \\
\hline & RI & $\mathrm{RS}$ & RI & $\mathrm{RS}$ \\
\hline Logarithmic & $9.9 \pm 2.6 \times 10^{7}$ & $2.0 \pm 1.2 \times 10^{4}$ & $3.8 \pm 1.2 \times 10^{7}$ & $1.4 \pm 1.2 \times 10^{8}$ \\
\hline Stationary & $7.1 \pm 2.3 \times 10^{7}$ & $1.7 \pm 0.5 \times 10^{4}$ & $4.3 \pm 1.3 \times 10^{7}$ & $5.5 \pm 3.5 \times 10^{7}$ \\
\hline
\end{tabular}

\section{Materials and Methods}

Bacterial cultures and alginate encapsulation. Spontaneous rifampicin-resistant mutants of Pseudomonas putida ATH2-1RI/9 and Acidovorax delafieldii ATH2-2RS/1 were used in this study. These mutants produce cyanide and reduce velvetleaf growth (as a liquid inoculum) to approximately the same extent as wild-type bacteria. To establish logarithmic growth phase and stationary growth phase cells, bacteria were cultured at $28^{\circ} \mathrm{C}$ with shaking in tryptic soy broth (TSB) for 10 or $17 \mathrm{~h}$ (LGP for Acidovorax delafieldii ATH22RS/1 and Pseudomonas putida ATH2-1RI/9 respectively) or 18 or $24 \mathrm{~h}$ (SGP for Acidovorax delafieldii ATH2-2RS/1 and Pseudomonas putida ATH2-1RI/9 respectively). Cells were collected by centrifugation, washed in sterile dilution buffer (SDB: $10 \mathrm{mM}$ potassium phosphate, $0.1 \mathrm{M} \mathrm{NaCl}, \mathrm{pH} 7.2$ ), and resuspended in one twentieth the original culture volume of TSB. Cells were encapsulated in alginate according to van Elsas et al. [22]. The alginate mixture contained $1 \%$ sodium alginate, $3 \%$ skim milk, and $3 \%$ bentonite in sterile TSB. Control formulations lacked bacteria. All alginate mixtures were extruded through a 22 gauge needle into sterile $0.1 \mathrm{M}$ $\mathrm{CaCl}_{2}$, allowed to harden for $1 \mathrm{~h}$, and washed in sterile TSB. After incubation overnight at $28^{\circ} \mathrm{C}$, the alginate beads were strained to remove excess liquid and stored at $4^{\circ} \mathrm{C}$. Beads were used to inoculate plants within 3 weeks of preparation. Bacterial levels in alginate beads were quantified by dissolving in SDB followed by serial dilutions with spread plate counts on half-strength TSA containing $100 \mu \mathrm{g}$ rifampicin/ $\mathrm{ml}$.

Plant growth experiments and rhizosphere analysis. Field soil was collected and processed according to Owen and Zdor [16]. The soil had not received herbicide treatment the previous year. Corn and fieldcollected velvetleaf seed were surface-disinfested, pregerminated, and planted in polypropylene tubes (length $110 \mathrm{~cm}$, width $2.5 \mathrm{~cm}$; using $45 \mathrm{~g}$ of autoclaved soil per tube according to Owen and Zdor [16]). Each seed received $10^{9}$ colony forming units (CFU) of Pseudomonas putida ATH2-1RI/9 or Acidovorax delafieldii ATH2-2RS/1 grown to $\log$ or stationary growth phases or the equivalent mass of control beads (range 4-50 mg for Pseudomonas putida ATH2-1RI/9 and 5-33 mg for Acidovorax delafieldii ATH2-2RS/1), the experiment being repeated three times ( 3 or 4 plants per experimental group for each experiment). This level of bacteria has been found to reduce velvetleaf growth as a liquid inoculum [16]. After 3 weeks of growth at $26^{\circ} \mathrm{C}$ plants were carefully removed from the tubes and length and weight measurements of both roots and shoots recorded. Rhizosphere levels of the bacterial inoculum and cyanide were quantified according to Owen and Zdor [16] by treating rhizosphere samples with $\mathrm{HCl}$ and trapping the released cyanide in $\mathrm{NaOH}$. Cyanide quantities were determined colorimetrically using $\mathrm{N}$-chlorosuccinimide and hydantoin-pyridine reagents. Data were analyzed using analysis of variance (ANOVA) at the 95\% confidence level. Pearson's correlation and two-way ANOVA were used to determine positive or negative significant trends.

\section{Results and Discussion}

Depending on the growth phase and bacterial isolate used, levels of inoculum bacteria ranged from $1 \times 10^{7}$ to $7 \times 10^{8} \mathrm{CFU} /$ milligram of alginate beads. Both $\log$ and stationary growth phase cultures gave similar levels of bacteria in the inoculum (data not shown). The highest bacterial levels in the inoculant were achieved with Acidovorax delafieldii ATH2-2RS/1. These levels of encapsulated inoculum cells are about 10-100 times greater than those reported for alginate-encapsulated $P$. fluorescens [22]. The higher inoculum levels achieved in this study may be attributed to the use of a nutrient-rich growth medium (TSB) or differences between strains in survival during the formulation procedure.

When comparing rhizosphere inoculant levels from LGP versus SGP cells, there were no statistically significant differences between the two growth phases (Table 1). In contrast, significant strain-plant differences were noted. Although Pseudomonas putida ATH2-1RI/9 colonized velvetleaf and corn roots to similar levels (approx. $10^{7} \mathrm{CFU} / \mathrm{g}$ root), velvetleaf rhizosphere Acidovorax delafieldii ATH2-2RS/1 populations were $10^{3}$ lower than the equivalent populations on corn roots. Interestingly the highest inoculant rhizosphere populations were found with RS on corn roots (Table 1).

The highest levels of rhizosphere $\mathrm{HCN}$ were found with Pseudomonas putida ATH2-1RI/9-inoculated velvetleaf, and ranged from approximately 53 to $68 \mathrm{mM}$ $\mathrm{HCN} / \mathrm{g}$ root (Table 2). No significant difference in $\mathrm{HCN}$ levels occurred between plants inoculated with SGP and LGP Acidovorax delafieldii ATH2-2RS/1 or Pseudomonas putida ATH2-1RI/9. However, HCN levels from Pseudomonas putida ATH2-1RI/9-colonized roots were consistently higher than $\mathrm{HCN}$ levels from Acidovorax delafieldii ATH2-2RS/1-inoculated roots for both plant species. The lowest levels of $\mathrm{HCN}(0.5-1 \mathrm{mM} \mathrm{HCN} / \mathrm{g}$ 
Table 2. Rhizosphere HCN ( $\mu \mathrm{M} / \mathrm{g}$ dry roots) recovered from velvetleaf and corn plants 21 days after inoculation with RI (Pseudomonas putida ATH2-1RI/9) and RS (Acidovorax delafieldii ATH2-2RS/1) bacteria. Cyanide levels were significantly $(p<0.05)$ lower on roots of both plant types for RS-inoculated plants compared with RI-inoculated plants. $n=10-12$ plants from three independent experiments.

\begin{tabular}{|c|c|c|c|c|}
\hline \multirow[b]{3}{*}{ Bacterial growth phase } & \multicolumn{4}{|c|}{ Mean $\pm 1 \mathrm{SE} \mu \mathrm{M} / \mathrm{g}$ dry root } \\
\hline & \multicolumn{2}{|c|}{ Velvetleaf } & \multicolumn{2}{|l|}{ Corn } \\
\hline & RI & $\mathrm{RS}$ & RI & $\mathrm{RS}$ \\
\hline Logarithmic & $53,524 \pm 11,403$ & $1029 \pm 1029$ & $14,772 \pm 4080$ & $1009 \pm 581$ \\
\hline Stationary & $68,022 \pm 19,249$ & $724 \pm 724$ & $11,378 \pm 3707$ & $502 \pm 179$ \\
\hline Control & $6791 \pm 2135$ & $279 \pm 279$ & $1564 \pm 700$ & $379 \pm 140$ \\
\hline
\end{tabular}

root) were recovered from Acidovorax delafieldii ATH2-2RS/1-inoculated roots. Moreover only 1 plant of the 11-12 LGP and SGP Acidovorax delafieldii ATH22RS/1-inoculated velvetleaf roots had detectable cyanide levels. Cyanide levels were significantly higher in Pseudomonas putida ATH2-1RI/9-colonized velvetleaf roots than in Pseudomonas putida ATH2-1RI/9-colonized corn roots. Previous studies suggest that the growth phase of bacteria is important to the production of secondary metabolites such as phenazine-1-carboxylic acid and cyanide that are important in plant-microbe interactions [6, 17, 18]. Vanderhove et al. [24] also reported the influence of growth phase on the survival of $P$. fluorescens in soil. However, in the current study cells formulated at different stages of growth did not differ significantly in their rhizosphere populations and effect on cyanide levels and plant growth. This lack of difference may suggest that the stage of growth of these two WRB prior to alginate formulation has a minimal effect on the influence of the bacteria in the rhizosphere. It also may be that the formulation process minimizes any differences between LGP and SGP cells relative to rhizosphere colonization and cyanide production that exist before formulation.

Velvetleaf shoot length and fresh weight for both LGP and SGP Pseudomonas putida ATH2-1RI/9-inoculated plants were significantly $(p<0.05)$ reduced relative to control plants (Fig. 1). Similar comparison for shoot dry weight showed some reduction, but the difference was not statistically significant. Reductions in shoot growth of Pseudomonas putida ATH2-1RI/9inoculated velvetleaf plants ranged from $68 \%$ to $87 \%$ of control plant values. Acidovorax delafieldii ATH2-2RS/ 1-inoculated velvetleaf plants did not show a statistically significant reduction for any of the velvetleaf shoot growth parameters compared with controls, with velvetleaf shoot measurements ranging from $88 \%$ to $100 \%$ of controls.

Velvetleaf root dry weight for both LGP and SGP Pseudomonas putida ATH2-1RI/9-inoculated plants were statistically significantly lower than controls (Fig. 2). Root dry weight of LGP and SGP Pseudomonas putida ATH2-1RI/9-inoculated plants was $61 \%$ and $56 \%$ respectively of the control value. Both LGP and SGP Acidovorax delafieldii ATH2-2RS/1-inoculated root lengths were significantly shorter than those of control plants, with mean root lengths being $88 \%$ of control values. Acidovorax delafieldii ATH2-2RS/1 inoculation did not reduce root dry weight relative to control plants. Most inoculated velvetleaf root systems appeared less branched compared with controls. Growth comparisons for inoculated corn plants (Figs. 1, 2), with the exception of shoot fresh weight of SGP Pseudomonas putida ATH2-1RI/9-inoculated plants, showed no statistically significant difference relative to controls.

The field use of Pseudomonas putida ATH2-1RI/9 and Acidovorax delafieldii ATH2-2RS/1 as weed control agents will necessitate an appropriate mode of storage and transfer to the target plants. These current results indicate that the alginate encapsulation method of Pseudomonas putida ATH2-1RI/9 and Acidovorax delafieldii ATH2-2RS/1 is possible. Up to $10^{11}$ cells per gram of alginate beads were recovered from samples kept at $4{ }^{\circ} \mathrm{C}$ for as long as 3 weeks. To simplify inoculant storage, ideally the beads should be in a dried form. Moist beads were used in this study because subsequent recovery of bacterial cells from dried preparations was significantly reduced (data not shown). van Elsas et al. [22] found that air-drying encapsulated bacteria in beads resulted in a significant reduction of viable cells compared with non-dried beads. Further research in the area of enhanced productivity and stability of Pseudomonas putida ATH2-1RI/9 and Acidovorax delafieldii ATH2$2 \mathrm{RS} / 1$ in dried alginate beads is needed. Hall and colleagues [10] tested the transport and survival of alginateencapsulated Pseudomonas aeruginosa through soil microcosms. They reported the greatest survival rates and soil distribution when using alginate-encapsulated inoculants. Alginate bead breakdown should act to release cells into the soil matrix, resulting in increased 

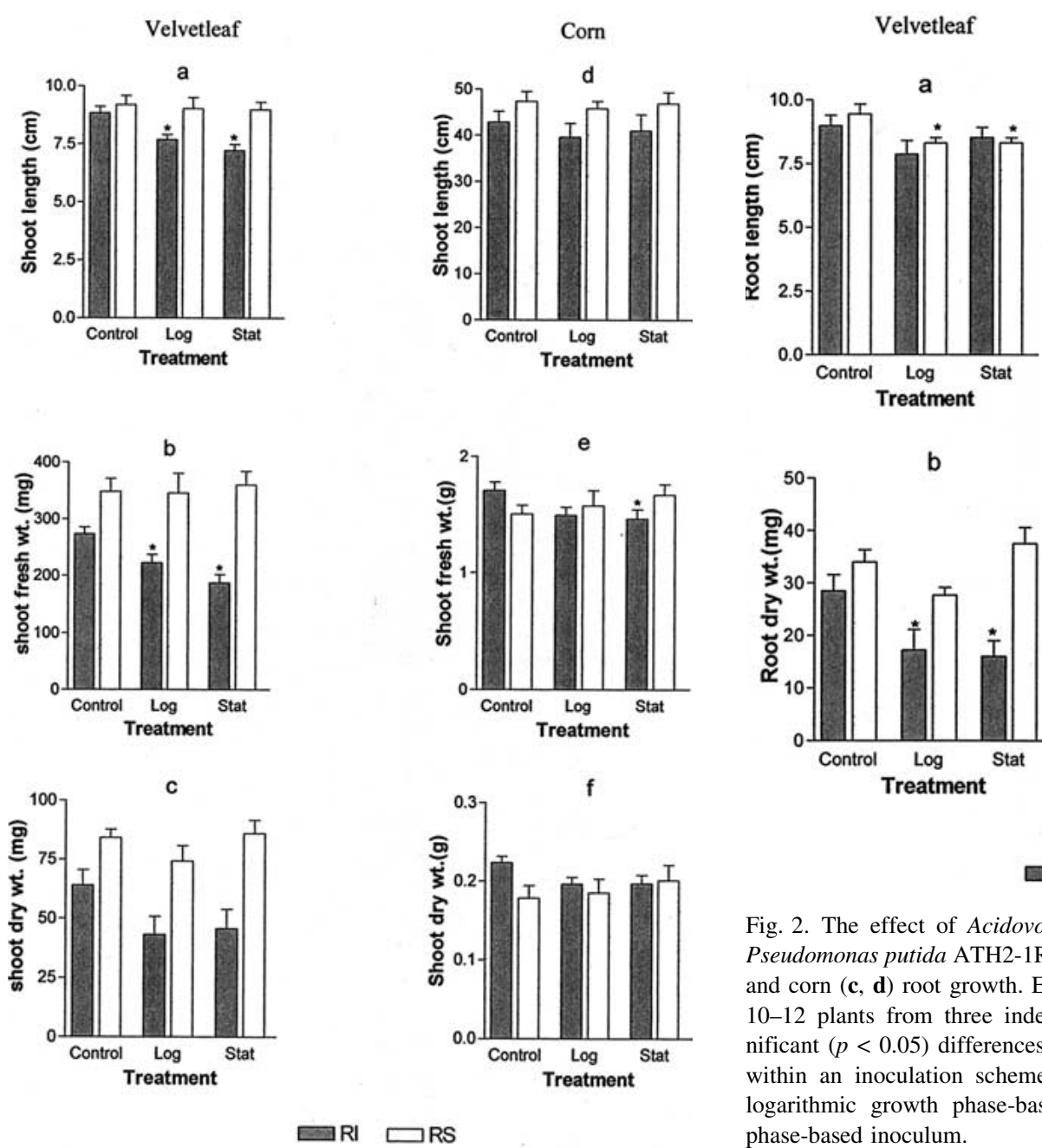

Fig. 1. The effect of Acidovorax delafieldii ATH2-2RS/1 (RS) and Pseudomonas putida ATH2-1RI/9 (RI) inoculation on velvetleaf (a-c) and corn (d-f) shoot growth. Each bar represents the mean $+1 \mathrm{SE}$ of 10-12 plants from three independent experiments. Statistically significant $(p<0.05)$ differences between control and inoculated plants within an inoculation scheme are indicated with an asterisk. Log, logarithmic growth phase-based inoculum; Stat, stationary growth phase-based inoculum.

persistence of the encapsulated agent in the rhizosphere of a target plant. Smit et al. [19] demonstrated the protective effect of alginate encapsulation of Pseudomonas fluorescens against lysis by bacteriophage $\Phi \mathrm{R} 2 \mathrm{f}$ in soil. Considering that the initial inoculant levels were approximately $2.2 \times 10^{7}$ cells/g soil, significant levels $\left(10^{7} \mathrm{CFU} / \mathrm{g}\right.$ root $)$ of Pseudomonas putida ATH2-1RI/9 cells were recovered from the rhizosphere. However, there was a significant reduction in the number of Acidovorax delafieldii ATH2-2RS/1 cells recovered from velvetleaf, but not corn. In this current study, the failure of Acidovorax delafieldii ATH2-2RS/1 to establish
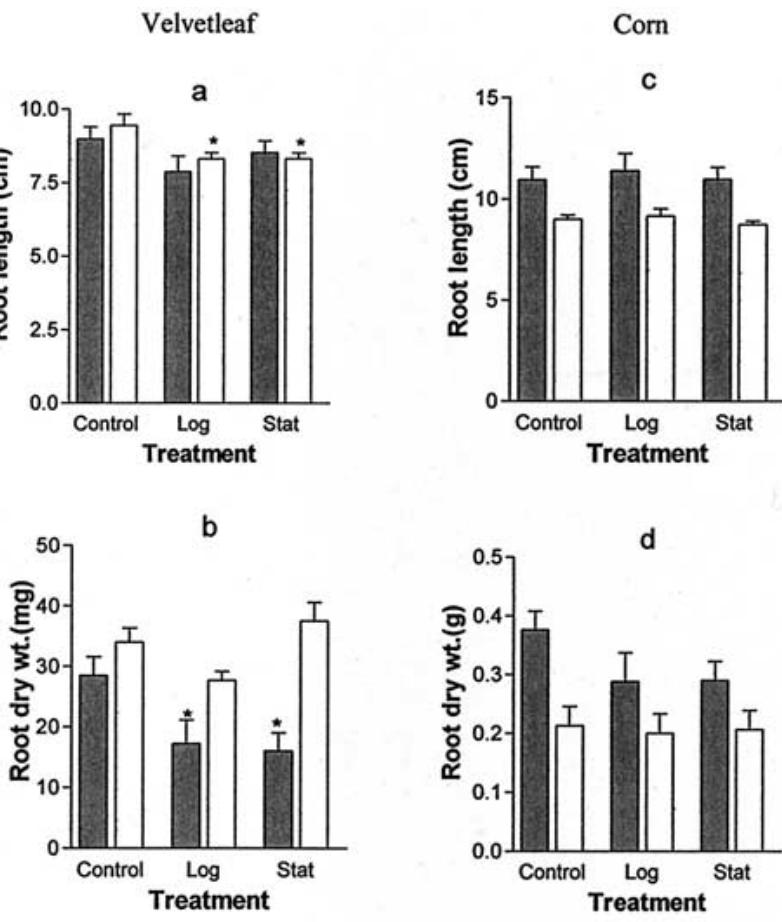

שRI $\square R S$

Fig. 2. The effect of Acidovorax delafieldii ATH2-2RS/1 (RS) and Pseudomonas putida ATH2-1RI/9 (RI) inoculation on velvetleaf $(\mathbf{a}, \mathbf{b})$ and corn $(\mathbf{c}, \mathbf{d})$ root growth. Each bar represents the mean $+1 \mathrm{SE}$ of $10-12$ plants from three independent experiments. Statistically significant $(p<0.05)$ differences between control and inoculated plants within an inoculation scheme are indicated with an asterisk. Log, logarithmic growth phase-based inoculum; Stat. stationary growth phase-based inoculum.

higher rhizosphere populations was reflected in minimal recovery of HCN from Acidovorax delafieldii ATH22RS/1-inoculated rhizospheres and the concomitant lack of effect on plant growth. This seems to indicate that increased levels of both bacteria and HCN correlate with reduction in some growth patterns and organ mass of the target plant. Previous work by Owen and Zdor [16] indicated that inoculation of velvetleaf and corn plants with liquid suspensions of Pseudomonas putida ATH21RI/9 and Acidovorax delafieldii ATH2-2RS/1 resulted in significant reductions in certain growth parameters of velvetleaf but not corn. It was suggested that the negative effect on velvetleaf may be due to metabolites of the bacteria such as HCN that may affect root metabolism and development by inhibiting enzymes such as cytochrome oxidase [3].

The basis for why Acidovorax delafieldii ATH22RS/1 effectively colonized the corn rhizosphere, but not the velvetleaf, rhizosphere as an alginate bead 
inoculum is unclear. It is possible that the release of bacterial cells from the beads in the rhizosphere differs between the two plants. This isolate did effectively colonize the velvetleaf rhizosphere as a liquid inoculum [16]. Presumably, there is some factor present or absent in the association with velvetleaf that differs in the association with corn roots. For example, the fibrous root system of the monocot may offer increased surface area, increasing the chance of contact for colonization when a liquid, but not a solid, inoculum is used. Such differential colonization based on variations in root system physiology is supported by the work of Nijhuis et al. [15], who found that grass rhizobacterial isolates from the grass rhizosphere exhibited distinct patterns of colonization at different locations of the same root system.

The current study suggests that alginate encapsulation is more compatible with Pseudomonas putida ATH2-1RI/9 than Acidovorax delafieldii ATH2-2RS/1. Thus, at least for the Pseudomonas putida ATH2-1RI/9 isolate, alginate formulation proved appropriate, allowing for stabilization, handling, and persistence of the organism at the target site. The differential success of the two alginate-formulated WRB isolates in the plant rhizosphere underlines the need to examine the response of specific WRB isolates to formulation in designing WRB-based weed control strategies.

\section{Literature Cited}

1. Alstrom S, Burns R (1989) Cyanide production by rhizobacteria as a possible mechanism of plant growth inhibition. Biol Fert Soils 7:232-238

2. Astrom B (1991) Role of bacterial cyanide production in differential reaction of plant cultivars to deleterious rhizosphere pseudomonads. Plant Soil 133:93-100

3. Bakker A, Schippers B (1987) Microbial cyanide production in the rhizosphere in relation to potato yield reduction and Pseudomonas spp-mediated plant growth-stimulation. Soil Biol Biochem 19:451-457

4. Bashan Y (1986) Alginate beads as synthetic inoculant carriers for slow release of bacteria that affect plant growth. Appl Environ Microbiol 51:1089-1098

5. Bashan Y, Hernandez J, Leyva L, Bacilio M (2002) Alginate microbeads as inoculant carriers for plant growth-promoting bacteria. Biol Fertil Soil 35:359-368

6. Blumer C, Hass D (2000) Mechanism, regulation, and ecological role of bacterial cyanide biosynthesis. Arch Microbiol 173:170 177

7. Boyetchko S (1999) Innovative applications of microbial agents for biological weed control. In: Mukerji K, Chamola B, Upadhyay $\mathrm{R}$ (eds). Biotechnological approaches in biocontrol of plant pathogens. New York: Kluwer Academic/Plenum Publishers, pp 73-97

8. Daigle D, Connick W, Boyetchko S (2002) Formulating a weed-suppressive bacterium in "pesta". Weed Technol 16:407413
9. Greaves M, Holloway P, Auld B (1998) Formulation of microbial herbicides. In: Burges H (ed). Formulation of microbial biopesticides. Dordrecht, The Netherlands: Kluwer Academic, pp 203-233

10. Hall B, McLoughlin A, Leung K, Trevors J, Lee H (1998) Transport and survival of alginate-encapsulated and free lux-lac marked Pseudomonas aeruginosa UG2Lr cells in soil. FEMS Microbiol Ecol 26:51-61

11. Kennedy A, Elliott L, Young F, Douglas C (1991) Rhizobacteria suppressive to the weed downy brome. Soil Sci Soc Am J 55:722727

12. Kremer R, Souissi T (2001) Cyanide production by rhizobacteria and potential for suppression of weed seedling growth. Curr Microbiol 43:182-186

13. Mooney H, Boyetchko S, Punja Z (1996) Development of application techniques for biological weed control using rhizobacteria. IX International Symposium on Biological Control of Weeds, Stellenbosch, South Africa, pp 297-299

14. Mortensen K (1998) Biological control of weeds using microorganisms. In: Boland G, Kuykendall L (eds). Plant-microbe interactions and biological control. New York: Marcel Dekker, pp 223248

15. Nijhuis E, Maat M, Zeegers I, Waalwijk C, van Veen J (1993) Selection of bacteria suitable for introduction into the rhizosphere of grass. Soil Biol Biochem 25:885-895

16. Owen A, Zdor R (2001) Effect of cyanogenic rhizobacteria on the growth of velvetleaf (Abutilon theophrasti) and corn (Zea mays) in autoclaved soil and the influence of supplemental glycine. Soil Biol Biochem 33:801-809

17. Schippers B, Bakker A, Bakker P, van Peer R (1990) Beneficial and deleterious effects of $\mathrm{HCN}$-producing pseudomonads on rhizosphere interactions. Plant Soil 129:75-83

18. Slininger P, VanCauwenberge J, Shea-Wilbur M, Bothast R (1998) Impact of liquid culture physiology, environment, and metabolites on biocontrol agent qualities. In: Boland G, Kuykendall L (eds). Plant-microbe interactions and biological control. New York: Marcel Dekker, pp 329-353

19. Smit E, Wolters A, Lee H, Trevors J, van Elsas J (1996) Interactions between a genetically marked Pseudomonas fluorescens strain and bacteriophage $\Phi R 2 \mathrm{f}$ in soil: effects of nutrients, alginate encapsulation, and the wheat rhizosphere. Microb Ecol 31:125-140

20. Stormo K, Crawford R (1992) Preparation of encapsulated microbial cells for environmental applications. Appl Environ Microbiol 58:727-730

21. Trevors J, van Elsas J, Lee H, van Overbeek L (1992) Use of alginate and other carriers for encapsulation of microbial cells for use in soil. Microb Releases 1:61-69

22. van Elsas J, Trevors J, Jain D, Wolters A, Heijnen C, van Overbeek L (1992) Survival of and root colonization by, alginateencapsulated Pseudomonas fluorescens cells following introduction into soil. Biol Fertil Soils 14:14-22

23. van Veen J, van Overbeek L, van Elsas J (1997) Fate and activity of microorganisms introduced into soil. Microbiol Mol Biol Rev 61:121-135

24. Vanderhove H, Merckx R, Wilmots H, Vlassak K (1991) Survival of Pseudomonas fluorescens inocula of different physiological stages in soil. Soil Biol Biochem 23:1133-1142

25. Wanner U, Egli T (1990) Dynamics of microbial growth and cell composition in batch culture. FEMS Microbiol Rev 75:19-44

26. Zohar-Perez C, Ritte E, Chernin L, Chet I, Nussinovitch A (2002) Preservation of chitinolytic Pantoae agglomerans in a viable form by cellular dried alginate-based carriers. Biotechnol Prog 18:1133-1140 